\title{
Study on Pricing Decisions of Cold-chain Logistics under Imperfectly Competitive Market
}

\author{
Shusheng Sun \\ School of Management \\ Wuhan University of Science and Technology \\ Hubei, 430081 \\ sunshusheng@wust.edu.cn
}

\author{
Kui Wang* \\ School of Management \\ Wuhan University of Science and Technology \\ Hubei, 430081 \\ 491178130@qq.com
}

\begin{abstract}
Abstrac - Cold-chain logistics exists throughout people's daily life. Numerous cold-chain logistics enterprises continuously look for methods of cost reduction and profit increase costs in business process. Pricing is the most important part involving each enterprise which participates in the whole process of distribution supply chain. Based on Stackelberg Game Theory, this paper introduced the fourth party logistics as the service provider of cold-chain logistics and studied retailer and the fourth party logistics' pricing strategies. Results show that cold-chain supply chain with centralized decision-making earns more profits than non-cooperative game decentralized decision-making. Example results have proved the effectiveness of the conclusion.
\end{abstract}

Keywords - cold-chain logistics; the fourth party logistics; pricing decisions; stackelberg

\section{INTRODUCTION}

Fresh agricultural product cold-chain logistics generally refers to the special supply system in which meat, poultry, aquatic products, vegetables, fruits, eggs and other fresh agricultural products are always in specified and physiological needed low temperature environment in procedures of product processing, storage, transportation, distribution and retail so as to guarantee product quality, quality safety, reduce losses and prevent pollution. Cold-chain logistics enterprises are in large operation scale earning good economic benefits. As the returns to scale increase, the actual marginal costs decline, which is completely accordance with the characteristics of imperfect market competition. Thus, appropriate pricing in numerous cold-chain logistics distribution process plays a crucial role in improving the operation efficiency of cold-chain logistics.

In 1999, Anderson Consulting [1] defined the fourth party logistics provider as "an organization integrating its own and other organizations' resources, capacity and technology to design, construct supply chain and provide extensive solutions for customers". Surveys show [2] that 90\% of enterprises cooperating with the fourth party logistics apply the strategy for above-mentioned reasons. Participants in the supply chain establish closer relationship with the fourth party logistics, support cost cutting actions, and flexibly take measures to cope with the uncertainties of supply and demand and finally positively impact the terminal end of supply chain.

Deng and Yano [3] studied the alliance pricing and production decision of single product manufacturer under the circumstance of capacity restricts and price sensitive demand within a limited cycle. Bernstein and Federgruen [4] studied the single cycle supply chain model, and the alliance pricing and purchasing problem when retailers avoid demand drain under imperfect competition. Mukho Padhyay and Setaputra [5] studied the price optimization decisions of retailer and recovery product handling service provider - the fourth party logistics under return policy. Liu Yuxiang and Zhang Jihui [6] found that there exist the only optimal pricing purchasing joint decision in supply chain by studying the joint contract made of restrictive returns contract and sales rebates contract aiming at problem that random demand depends on the price. Liu Xiaoyun and Wang Yanjie [7] studied when ordinary enterprises are not equipment with professional skills of processing reverse logistics, and obtained the optimal price strategy of the fourth party logistics and retailer through game theoretical model. Li Jianfeng, etc. [8] used share option and game theory to analyze the coordination between the optimal decision and supply chain in the environment of uncertain logistics service so as to obtain the integrator's optimal procurement amount and the supplier's optimal option pricing decision. Jiang Shiying, etc.[9] established centralized decision-making model considering avoiding product risk, environmental protection and other factors, and analyzed revenue sharing coefficients, risk aversion and the impact of whole supply chain member enterprises on each other.

Different with above literatures, this article studied cold-chain logistics service provider, i.e. The secondary cold-chain supply chain pricing model made of the fourth party logistics and related retailer. Apply the realistic micro background of imperfectly competitive market and use Stackelberg Game Theory model to research the pricing strategy of retailer and the fourth party logistics with distributed decision. In the whole game theory, there are two game parties, the leader and the follower. The leader knows that the follower will observe their choices and the latter will remain their strategy. Thus the leader has the advantage of first 
move. But the leader must make decisions and commitment without random modification or strategy withdrawal, which means that as long as the leader has made decisions, the leader must insist to the end. Or the advantage of first move will disappear. Then come into the conclusion through practical examples after comparing decentralized decision-making and centralized decision-making: the profit of the whole supply chain with centralized decision-making will reach the optimal level.

\section{PROBLEM STATEMENT AND FUNDAMENTAL ASSUMPTION}

Assume the whole supply chain system is made up of a manufacturer, a retailer, and a fourth party logistics service provider and the fourth party logistics party has functions of the third party logistics. Cold-chain product manufacturer entrusts the fourth party logistics to deal with the product transportation issue by paying commission M. 4PL supplier purchases products from manufacturer at the price of $h$ and then transports to the retailer after simple processing. Assume customers are provided with products all at the same price with no change. Only the single-track fourth party logistics service provider and the retailer are taken into consideration in the whole process of pricing.

Relevant parameters show that 4PL purchases products at the unit cost of $c_{1}$ and wholesale price of $p_{1}$, available to satisfy all order demand of relevant retailers. p1 is the decision variable of 4PL and $p_{1}>c_{1}$, Retailer obtains commodities from 4PL and sells to customers at the price of $p_{2}$, at selling costs of $c_{2}$, with relevant loss costs of $\mathrm{s}$ during the transportation, and product basic demand amount of a product occupation proportion before and after entering into market as $\rho$, product price elasticity of demand as $\alpha_{i}(\mathrm{i}=1,2$,), price sensitivity of demand for market as $\beta_{i} \quad(i=1,2$,$) , product$ demand and customer's sensitivity to incomplete market completion policy as $\gamma$ and $\lambda$ respectively, product loss as $R$, cardinal number of loss as $\mathrm{b}$, product residual value as e, and product loss amount meeting the condition of $\mathrm{R}=\mathrm{b}+\lambda \mathrm{s}$.

Demand function of 4PL manufacturer and retailer are impacted by market price respectively and fluctuates depending on the influence of incomplete competition market policy. Based on the researches of Yue and Liu [10], simplify the model, and assume that demand function as the linear function of price, the demand of $4 \mathrm{PL}$ market as $\mathrm{D}_{1}=(1-$ $\rho) \mathrm{a}-\alpha_{1} \mathrm{p}_{1}+\beta_{1} \mathrm{p}_{2}+\gamma \mathrm{s}$, retailer market demand function $\operatorname{asD}_{2}=\rho \mathrm{a}-\alpha_{2} \mathrm{p}_{2}+\beta_{2} \mathrm{p}_{1}$.

4PL service provider provides logistics information and transport service for manufacturer and retailer, service price of transported unit product as $\mathrm{w}$, logistics operation cost of unit product as $c_{3}$. Service price of the whole supply chain process and the operation cost are under the joint burden of manufacturer and retail, assume its operation cost as $\mathrm{kw}, \mathrm{k} \in[0$, $1]$.

Assume the profit function of $4 \mathrm{PL}$ and retailer is $v_{1}$ and $v_{2}$, total profit as v. Obtain relevant profit model from above assumptions:

$$
\begin{gathered}
\mathrm{v}_{1}=\mathrm{p}_{1} \mathrm{D}_{1}+\mathrm{e}\left(\mathrm{R}-\mathrm{D}_{1}\right)-\left(\mathrm{h}+\mathrm{c}_{1}\right) \mathrm{R}+\mathrm{M} \\
\mathrm{v}_{2}=\left(\mathrm{p}_{2}-\mathrm{c}_{2}-\mathrm{kw}\right) \mathrm{D}_{2}+(\mathrm{h}-\mathrm{s}) \mathrm{R}
\end{gathered}
$$

$$
\begin{aligned}
& \mathrm{v}=\mathrm{v}_{1}+\mathrm{v}_{2}=\left(\mathrm{p}_{1}-\mathrm{e}\right) \mathrm{D}_{1}+\left(\mathrm{p}_{2}-\mathrm{c}_{2}-\mathrm{kw}\right) \mathrm{D}_{2} \\
& +\left(\mathrm{e}-\mathrm{s}-\mathrm{c}_{1}\right) \mathrm{R}+\mathrm{M}
\end{aligned}
$$

\section{COLD-CHAIN LOGISTICS PRICING DECISION-MAKING BASED ON IMPERFECT MARKET COMPETITION}

\section{A. Centralized pricing decision-making}

In the whole centralized pricing decision-making, 4PL service provider and retailer conduct cold-chain product pricing with the whole supply chain profit maximization as the starting point, and their own profit maximization as the objective of pricing. Thus, to maximize the whole supply chain profit $\mathrm{v}$, it requires to meet the condition $\frac{\partial \mathrm{V}}{\partial \mathrm{P} 2}=0$, thus acquire:

$$
\mathrm{p}_{2} *=\frac{\left(\beta_{1}+\beta_{2}\right) \mathrm{p}_{1}+\left(\mathrm{c}_{2}+\mathrm{kw}\right) \alpha_{2}-\mathrm{e} \beta_{1}+\rho \mathrm{a}}{2 \alpha_{2}}
$$

$\mathrm{p}_{1}^{*}=\frac{\left(\mathrm{kw}+\mathrm{c}_{2}\right) \beta_{2}-\left(\beta_{1}-\alpha_{2}+\beta_{2}\right) \mathrm{p}_{2}-(1-\rho) \mathrm{a}-\mathrm{rs}-\mathrm{e} \alpha_{1}}{\beta_{2}-2 \alpha_{1}}$

The current profit is

$$
\begin{aligned}
\mathrm{v}^{*}= & \frac{\left(\mathrm{kw}+\mathrm{c}_{2}\right) \beta_{2}+(\mathrm{c}-2 \mathrm{e}) \beta_{1}+(1-\rho) \mathrm{a}-2 \mathrm{rs}}{2 \alpha_{2}\left(\beta_{2}-2 \alpha_{1}\right)^{2}} \\
& +\left(\mathrm{e}-\mathrm{s}-\mathrm{c}_{1}\right) \mathrm{R}+\mathrm{M}
\end{aligned}
$$

It can be known as mentioned above: with centralized decision-making, for cold-chain products, when the cost is low and loss in the transportation is small, i.e.s $\rightarrow 0$, the sales volume and earning is high. When the loss in transportation and cost increases, the price of $p_{2}^{*}$ exceeds consumers' expectation, sales volume will fall and consumers will not even purchases but consume other related substitute goods. So the loss cost in transportation should satisfy the condition:

$\mathrm{s} \leqslant \mathrm{p}_{2} *=\frac{\left(\beta_{1}+\beta_{2}\right) \mathrm{p}_{1}+\left(\mathrm{c}_{2}+\mathrm{kw}\right) \alpha_{2}-\mathrm{e} \beta_{1}+\rho \mathrm{a}}{2 \alpha_{2}}$

\section{B. Decentralized decision-making}

With decentralized decision-making, enterprises in each procedure of cold-chain supply chain must set their own profit maximization as the decision-making purpose. Assume 4PL as the leader setting price according to the product purchased from manufacturer and the transportation loss cost expectation. Retailer is the follower and set price according to the behavior of leader 4PL. Make decentralized pricing on cold-chain products based on Stackelberg Non-cooperative Game Theory. Equilibrium result of the game theory model obtained from inductive analogical method:

Under the price strategy $\left(p_{1}, h\right)$ of 4PL, the price and loss of retail response price functions are:

$$
\mathrm{p}_{2}=\frac{\left.2 \lambda \lambda(1-\rho) \mathrm{a}+\beta_{2} \mathrm{p}_{1}+\mathrm{c}_{2} \alpha_{2}\right]+\gamma(\lambda \mathrm{h}-\gamma \mathrm{c} 2-\mathrm{b})}{4 \lambda \lambda_{2}-\gamma^{2}}
$$




$$
s=\frac{\left[(1-\rho) a+\beta_{1} p_{2}+c_{1} \alpha_{1}\right]+2 \alpha_{1}\left(\lambda \lambda-\gamma c_{1}-b\right)}{4 \lambda \lambda_{1}-\gamma^{2}}
$$

Assume that retailer applies above-mentioned price strategy, when $-2 \alpha_{2}\left(4 \lambda \alpha_{1}-\gamma^{2}\right)+4 \lambda \beta_{1} \beta_{2}<0, \quad 4 \lambda \alpha_{1}-\gamma^{2}>0$, the optimal price strategy of 4PL enterprise is:

$$
\begin{aligned}
& \mathrm{p}_{1}^{*}= \frac{1}{2 \lambda \lambda_{2}\left(2 \alpha_{2}-\beta_{1} \mathrm{G}_{1}\right)-\lambda \mathrm{G}_{2}\left(\lambda \lambda_{2}-\beta_{2} \mathrm{H}_{1}\right)} * \\
&\left\{\left[\left(\rho \alpha+\beta_{2}\left(\mathrm{~F}_{1}-\mathrm{F}_{2}\right)+\mathrm{e}\left(\alpha_{2}-\beta_{1} \mathrm{G}_{1}\right)+\lambda \mathrm{G}_{2}\left(\mathrm{e}-\mathrm{c}_{2}\right)\right]-\right.\right. \\
& \quad \frac{1}{2 \lambda \mathrm{H}_{2}}\left(\lambda \lambda_{2}-\beta_{2} \mathrm{H}_{1}\right)\left[\left(\mathrm{p}_{2}-\mathrm{e}\right)\right] \beta_{2} \mathrm{H}_{1}+ \\
&\left.\left(\mathrm{e}-\mathrm{c}_{2}\right) \lambda \lambda_{2}-\mathrm{b}-\lambda\left(\mathrm{F}_{3}-\mathrm{F}_{4}\right)\right\} \\
& \mathrm{h}^{*}= \frac{1}{2 \lambda \lambda \lambda_{2}}\left\{\left[\left(\mathrm{p}_{2}-\mathrm{e}\right)\right] \beta_{2} \mathrm{H}_{1}+\left(\mathrm{e}-\mathrm{c}_{2}\right) \lambda \lambda_{2}\right. \\
&\left.-\left[\mathrm{b}+\lambda\left(\mathrm{F}_{3}-\mathrm{F}_{4}\right)\right]-\lambda \mathrm{G}_{2} \mathrm{p}^{*}\right\}
\end{aligned}
$$

There into:

$$
\begin{aligned}
\mathrm{F}_{1} & =\frac{2 \lambda \lambda\left[(-\rho) \mathrm{a}+\mathrm{c}_{1} \alpha_{1}\right]}{4 \lambda \lambda_{1}-\gamma^{2}} \\
\mathrm{~F}_{2} & =\frac{\gamma\left(\left(\mathrm{rc}_{1}+\mathrm{b}\right)\right.}{4 \lambda \lambda_{1}-\gamma^{2}} \\
\mathrm{~F}_{3} & =\frac{\left.\gamma(1-\rho) \mathrm{a}+\mathrm{c}_{1} \alpha_{1}\right]}{4 \lambda \lambda_{1}-\gamma^{2}} \\
\mathrm{~F}_{4} & =\frac{2 \alpha_{1}\left(\gamma \alpha_{1}+\mathrm{b}\right)}{4 \lambda \alpha_{1}-\gamma^{2}} \quad \mathrm{G}_{2}=\frac{\gamma \beta_{1} \mathrm{p}_{2}}{4 \lambda \lambda_{1}-\gamma^{2}} \\
\mathrm{G}_{1}= & \frac{2 \lambda \lambda_{1} \mathrm{p}_{2}}{4 \lambda \lambda_{1}-\gamma 2} \quad \mathrm{H}_{2}=\frac{2 \alpha_{1} \lambda \mathrm{h}}{4 \lambda \alpha_{1}-\gamma^{2}} \\
\mathrm{H}_{1}= & \frac{\gamma \lambda}{4 \lambda \alpha_{1}-\gamma^{2}}
\end{aligned}
$$

Under the price strategy of 4PL as the leader, the pricing of retailer as the follower is:

$\mathrm{p}_{2} *=\frac{2 \lambda \lambda\left[(-\rho) \mathrm{a}+\beta_{2} \mathrm{p}_{2} *+\mathrm{c}_{2} \alpha_{2}\right]+\gamma\left(\lambda \mathrm{h} *-\gamma \gamma_{1}-\mathrm{b}\right)}{\left(4 \lambda 4_{2}-\gamma^{2}\right)}$ $\mathrm{s}^{*}=\frac{\gamma\left[(1-\rho) \mathrm{a}+\beta_{1} \mathrm{p}_{2} *+\mathrm{c}_{1} \alpha_{1}\right]+2 \alpha_{1}\left(\lambda \lambda *-\gamma \gamma_{1}-\mathrm{b}\right)}{4 \lambda \lambda_{1}-\gamma^{2}}$

Then substitute 4PL and retailer adjusted price $p_{1}^{*}, p_{2}^{*}, h^{*}$ $s *$ into formula $v$ and obtain:

$$
\begin{aligned}
\mathrm{v} * *= & \frac{4 \gamma\left[(1-\rho) \mathrm{a}+\mathrm{c}_{2} \beta_{1}+\mathrm{c}_{1} \alpha_{1}\right]+2 \gamma \gamma_{1}\left(\lambda \lambda *-\gamma \gamma_{1}-\mathrm{b}\right)+4 \mathrm{rs}}{16 \alpha_{2}\left(\beta_{2}-2 \alpha_{1}\right)^{2}\left(4 \lambda 4_{1}-\gamma^{2}\right)^{2}} \\
& +(\mathrm{e}-\mathrm{s}-\mathrm{c} 1) \mathrm{R}+\mathrm{M}
\end{aligned}
$$

It is not hard to find after comparing with the profit $v^{*}$ of centralized decision-making and obtain $v^{* *}<v^{*}$. Retail price is higher than the price with centralized decision-making and sales volume is smaller than the volume with centralized decision-making, i.e. the lowest sales volume is obtained at a high retail price with decentralized decision-making so that the whole supply chain profit is the least.

\section{PROFIT MAXIMIZATION PRICING STRATEGY IN COLD-CHAIN LOGISTICS SUPPLY CHAIN}

The total profit of the whole supply chain with decentralized decision-making must be smaller than the system profit with centralized decision-making. Enterprises in each procedure of the system must comprehensively consider the profit balance of the whole system while concerning their own profit maximization. Thus, the purpose of profit maximization supply chain pricing strategy is under the condition of whole profit maximization, i.e. to set product wholesale price and related logistics service price based on the condition of the optimal pricing of $p_{1}^{*}, p_{2}^{*}$ for reasonable distribution of the whole supply chain profits for profit balance.

Assume that in the cooperative game theory coordination decision-making, enterprises in each procedure have the same profit growth rate compared with centralized decision-making. Assume the profit growth rate in each procedure as q. On the condition that total profit $v^{*}=(1+q) v^{* *}$, calculate that $\mathrm{q}=$ $\frac{v^{*}-v^{* *}}{v^{* *}}$. So profits of enterprises in each procedures after benefit coordination decision-making are: profit of 4PLlogistics service provider $v_{1}^{*}=(1+q) v_{1}^{* *}$, profit of retailer $v_{2}^{*}=(1+$ q) $v_{2}^{* *}$. Thus, get the conclusion that enterprises in each procedures are profitable in the cooperative game, i.e. in the centralized supply pricing decision-making and when their profit maximizes, the whole supply chain profit can be maximized, which means in the centralized decision-making, earnings of 4PL logistics service provider and retailer have achieved pareto improvement and total profit of the whole cold-chain can be maximized.

\section{V.ANALYSIS OF EXAMPLES}

Assume that there exist a cold-chain product supply chain made up of 4PL logistics service provider and retailer in the imperfect competition market. Assume the demand function of 4PL market $D_{1}=2500+5.5 p_{1}+3.2 p_{2}$, market demand function of retailer $D_{2}=2000+4 p_{1}-2.8 p_{2}$, and costs of 4PL logistics service provider and retailer are $c_{1}=4, c_{2}=$ 3 respectively. Product occupation proportion before and after 
entering into market is $\rho=0.75$. As shown in table 1 , each major parameter data table, substitute each parameter value into corresponding price demand function for comparison and obtain that table 2 is the result and corresponding comparison in different decision-makings.

It can be obtained from the data analysis in table 2: overall income of cold-chain supply chain in centralized decision making is larger than the supply chain earnings with decentralized decision-making, and retailer's selling price and product demand amount are higher than that with decentralized decision-making respectively. Thus the price of cold-chain product is reduced through centralized decision-making but relevant sales scale is obtained and the max profit of the whole supply chain is achieved. But decentralized decision-making has played a double marginal utility with no profit maximization effect achieved.

TABLE I MAJOR RELEVANT PARAMETER DATA TABLE

\begin{tabular}{cccccccccc}
\hline Parameter & $\mathbf{a}$ & $\mathbf{b}$ & $\boldsymbol{\alpha}_{1}$ & $\boldsymbol{\alpha}_{2}$ & $\boldsymbol{\beta}_{1}$ & $\boldsymbol{\beta}_{2}$ & $\boldsymbol{\lambda}$ & $\boldsymbol{\gamma}$ & $\mathbf{e}$ \\
\hline $\begin{array}{c}\text { Numerical } \\
\text { value }\end{array}$ & 2000 & 800 & 5.5 & 2.8 & 3.2 & 4 & 0.1 & 0.3 & 25.3 \\
\hline
\end{tabular}

TABLE II EQUILIBRIUM RESULT AND COMPARISON WITH DECENTRALIZED DECISION-MAKING AND CENTRALIZED DECISION-MAKING

\begin{tabular}{ccc}
\hline Item & $\begin{array}{c}\text { Decentralized } \\
\text { decision-making }\end{array}$ & $\begin{array}{c}\text { Centralized } \\
\text { decision-making }\end{array}$ \\
\hline Retailer's price & 76.38 & 58.32 \\
4PLlogistics & 58.35 & 45.29 \\
enterprise's price & 1378.24 & 3324.19 \\
Retailer's profit & 2932.57 & 6925.74 \\
4PLlogistics & 4310.81 & 10249.93 \\
enterprise's profit & & \\
Gross profit &
\end{tabular}

\section{CONCLUSION}

It has a significant effect that introduction of 4PL logistics service provider as an outsourcer in cold-chain logistics under imperfect market competition. It has an important management issue that how enterprises in each procedure can achieve max profit and promote cooperation between enterprises and realize benefit win-win in the whole cold-chain logistics supply chain. This paper discussed product pricing problem in cold-chain logistics supply chain, compared profits in two decision-making modes: centralized pricing and decentralized pricing in game theory model, and finally concluded that centralized pricing decision-making mode can help increase the profit of the whole supply chain. The studies are not consummated. This paper focus on two main subjects: 4PL supplier and retailer, not considering enterprises in other procedures of the whole supply chain such as manufacturer, etc. Secondly, the research did not fully consider the loss in product transportation and time window problem. Besides, it is suggested to consider a dynamic model including factors such as the product demand changing with time and season, product type, and consumer preference, etc. can be taken into consideration.

\section{REFERENCES}

[1] BADED, MUELLER, YOUD B. Technology in the next generation of supply chain outsourcing: leveraging capabilities of fourth party [J] Logistics Ascet, 1999(1), pp. 38-40.

[2] WIN A. The value a 4PL provider can contribute to an organization [J]. International Journal of Physical Distribution \& Logistics Management, 2008,38 (9), pp. 674-684.

[3] DENG S, YANO C A. Joint production and pricing decisions with setup costs and capacity constraints [J]. Management Science, 2006, 52 (5), pp. 741-756.

[4] BERNSTEIN F, FEDERGEUEN. Pricing and replenishment strategies in a distribution system with competing retailers $[\mathrm{J}]$. Operations Research, 2003, 51 (3), pp. 409-426.

[5] MUKHOPADHYAYSK, SATAPUTRA R. The role of 4PL as the reverse logistics integrator: Optimal pricing and return policies [J]. International Journal of Physical Distribution \& Logistics Management, $2006,36(9)$, pp. 716-729.

[6] Liu Yushuang, Zhang Jihui. Coordination contract and optimal decision-making when demand depends on price $[\mathrm{J}]$. Journal of Bohai University (JCR-SCI), 2013,34 (1), pp. 85-89. In chinese.

[7] Liu Xiaoyun, Wang Yanjie. Studies of pricing decision-making of reverse logistics in the competition environment [J]. Journal of Bohai University (JCR-SCI), 2016 ,37(1),pp. 11-14. In chinese

[8] Li Jianfeng, Huang Zuqing, Chen Shiping. Logistics service supply chain coordination mechanism based on share option [J]. Computer Integrated Manufacturing System, 201319 (6), pp. 1377-1384. In chinese.

[9] Jiang Shiying, Ma Chunyan. Green supply chain contract coordination model considering retailer's risk attitude [J]. Industrial Engineering, 2015, 18(3), pp. 30-35. In chinese.

[10] YUE X, LIU J. Demand forecast sharing in a dual-channel supply chain [J]. European Journal of Operational Research, 2006, 174(1), pp. 646-667. 